\title{
Article \\ Characterization of Two BAHD Acetyltransferases Highly Expressed in the Flowers of Jasminum sambac (L.) Aiton
}

\author{
Yuting Wang ${ }^{1}$, Hongliang Zhang ${ }^{1}$, Chao Wan ${ }^{1}$, Xian He ${ }^{1}$, Jinfeng Huang ${ }^{1}$, Meiling Lyu ${ }^{1,2}$, Yuan Yuan ${ }^{1,2}$ \\ and Binghua $\mathrm{Wu}^{1,2, *(\mathbb{D})}$ \\ 1 Ornamental Horticulture Department, College of Horticulture, Fujian Agriculture and Forestry University, \\ No. 15, Shang Xia Dian Road, Cangshan District, Fuzhou 350002, China; yutingwang123456@163.com (Y.W.);

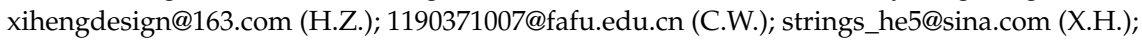 \\ 1190371002@fafu.edu.cn (J.H.); mllyu@fafu.edu.cn (M.L.); yuanyuan@fafu.edu.cn (Y.Y.) \\ 2 The Fujian Provincial Key Laboratory of Plant Functional Biology, College of Life Sciences, Fujian Agriculture \\ and Forestry University, No. 15, Shang Xia Dian Road, Cangshan District, Fuzhou 350002, China \\ * Correspondence: Binghua.wu@fafu.edu.cn; Tel.: +86-18850498434
}

check for updates

Citation: Wang, Y.; Zhang, H.; Wan, C.; He, X.; Huang, J.; Lyu, M.; Yuan, Y.; Wu, B. Characterization of Two BAHD Acetyltransferases Highly Expressed in the Flowers of Jasminum sambac (L.) Aiton. Plants 2022, 11, 13. https://doi.org/10.3390/ plants11010013

Academic Editors: Marcello Iriti and Sara Vitalini

Received: 30 November 2021 Accepted: 20 December 2021 Published: 21 December 2021

Publisher's Note: MDPI stays neutral with regard to jurisdictional claims in published maps and institutional affiliations.

Copyright: (c) 2021 by the authors. Licensee MDPI, Basel, Switzerland. This article is an open access article distributed under the terms and conditions of the Creative Commons Attribution (CC BY) license (https:/ / creativecommons.org/licenses/by/ $4.0 /)$.

\begin{abstract}
Volatile benzenoid compounds are found in diverse aromatic bouquets emitted by most moth-pollinated flowers. The night-blooming Jasminum sambac is widely cultivated worldwide in the tropics and subtropics for ornamental and industrial purposes owing to its fragrant flowers. Benzylacetate is a characteristic constituent in jasmine scent which makes up to approximately $20-30 \%$ of the total emission in the headspace or extract, but the biosynthesis enzymes and the encoding genes have not yet been described. Here, we identify two cytosolic BAHD acyltransferases specifically expressed in the petals with a positive correlation closely to the emission pattern of the volatile benzenoids. Both JsBEAT1 and JsBEAT2 could use benzylalcohol and acetate-CoA as substrates to make benzylacetate in vitro. The recombinant GST-JsBEAT1 has an estimated apparent $K_{\mathrm{m}}$ of $447.3 \mu \mathrm{M}$ for benzylalcohol and $546.0 \mu \mathrm{M}$ for acetate-CoA, whereas in the instance of the His-JsBEAT2, the $K_{\mathrm{m}}$ values are marginally lower, being 278.7 and $317.3 \mu \mathrm{M}$, respectively. However, the catalytic reactions by the GST-JsBEAT1 are more efficient than that by the His-JsBEAT2, based on the steady-state $k_{\text {cat }}$ parameters. Furthermore, ectopic expression of JsBEAT1 and JsBEAT2 in the transgenic $P$. hybrida plants, driven by a flower-specific promotor, significantly enhances the biosynthesis of benzylbenzoate and benzylacetate, as well as the total VOCs.
\end{abstract}

Keywords: Jasminum sambac; Oleaceae; BAHD acyltransferases family; benzyl alcohol O-acetyltransferase (BEAT); enzyme kinetics; floral scent; benzenoid; benzyl acetate

\section{Introduction}

Plants utilize a wide array of specialized metabolites to interact with changing environments and to safeguard their survival and reproduction [1-3]. These structurally different molecules produced by plants are usually classified based on their biosynthetic origin, such as terpenoids, benzenoids/phenylpropanoids, fatty acid derivatives and amino acid derivatives. Large portions of the plant-specialized metabolites are lipophilic small molecules with high vapor pressure at ambient temperatures, and thus called volatile organic compounds (VOCs). More than 1700 VOCs have been identified from 90 different plant families, and mostly are synthesized and released, with high abundance and diversity, from the flowers in many flowering plants [4]. Floral VOCs play important roles in the attraction of pollinators and protection against pathogens, parasites, and herbivores [5-7].

Flowers of the night-blooming plant Jasminum sambac (L.) Aiton (Oleacese) emit a strong fragrance which has long been used as raw material in the perfume industry and in scented tea. While jasmine absolute is the common name of the aroma product made by distillation from subsequent hexane and ethanol extractions of the flowers, the VOCs are enriched in benzyl acetate, linalool and $(\mathrm{E}, \mathrm{E})-\alpha$-Farnesene [8]. Floral VOCs in several 
Jasminum species have also been reported [9-14]. Although variation in the composition of the floral scent exists depending on the species/varieties, cultivation practices, and season, benzyl acetate is the predominant benzenoid ester, accounting for almost $90 \%$ of the volatile benzenoid/phenylpropanoids. However, the biosynthetic enzymes and the encoding genes are rarely explored in this genus.

Phytochemically, most floral benzenoid esters are produced by acyl-CoA-dependent acylation performed by a group of acyltransferases, the Benzylalcohol O-acetyl-, Anthocyanin $O$ hydroxycinnamoyl-, Hydroxycinnamoyl/benzoyl-CoA: Anthranilate $N$-hydroxycinnamoyl/ benzoyl-, and Deacetylvindoline 4-O- acetyltransferases (BAHD) superfamily [15-18]. These enzymes catalyze the transfer of an acyl group from activated acyl donor molecules, Coenzyme A or CoA thioesters, to acyl acceptor molecules, oxygen- and nitrogen-containing substrates, producing esters and amides, respectively [19]. A benzyl-alcohol acetyl-CoA acetyltransferase (BEAT) from Clarkia breweri involved in floral VOC synthesis was first identified and cloned in 1998 [17]. Since then, more than 69 biochemically characterized BAHD acyltransferases have been reported, and they share two conserved motifs, HXXXD and DFGWG, but with low overall sequence identity at the amino acid level of $25-34 \%[19,20]$. Phylogenetically, the plant BAHD family could be divided into five clades [15] or further refined to eight clades [21]. The versatile reactions catalyzed by these divergent enzymes make it difficult to predict their function solely based on the encoding sequences.

In this study, two highly expressed and volatile benzenoid profile-correlated candidate $B A H D$ genes are identified and characterized from J. sambac petals. The enzymatic activities of the recombinant proteins were determined using common substrates benzyl-alcohol and acetyl-CoA. Finally, transgenic P. hybrida plants ectopically expressing these two $J$. sambac genes in the flowers showed enhanced production of the major benzenoid volatiles, suggesting that both are functional BAHD in planta. Our results provide molecular and biochemical evidence for further deciphering the genetic control of volatile benzenoid production in the flowers of $J$. sambac.

\section{Results}

\subsection{Profiling Floral Scent Volatiles in J. sambac}

The flower of J. sambac starts to emit fragrance when it opens at dusk. We sampled the open flowers at $3 \mathrm{~h}$ intervals and determined the volatile profiles using methanol extracts via a GC-MS. The total volatiles peaked at around midnight and featured large parts of terpenoids and benzenoids (Figure 1). The peak-corresponding compounds were putatively identified based on the RI (Kovats retention indices) and MS spectrum matching the NIST (National Institute of Standards and Technology) GC-MS databases (Figure S1), and authentic reference substance of $\alpha$-farnesene, benzyl acetate, benzyl alcohol, and (R/S)linalool were also used for the confirmation. The abundant constituents were $\alpha$-farnesene, linalool, germacrene, benzyl acetate, and other benzoic acid esters (Figure 1), consistent with data reported in earlier literature [10,13].

We quantified the benzenoid compounds in the petal extracts using an internal standard as a reference and found that cis-3-hexenylbenzoate and benzyl acetate were the two most enriched compounds, followed by methylanthranilate and benzoic acid-2-propenyl ester at about the midnight timepoints (Table 1). Thus, the petal extract was characterized of a mixture of benzenoid esters with some variations during the time. 


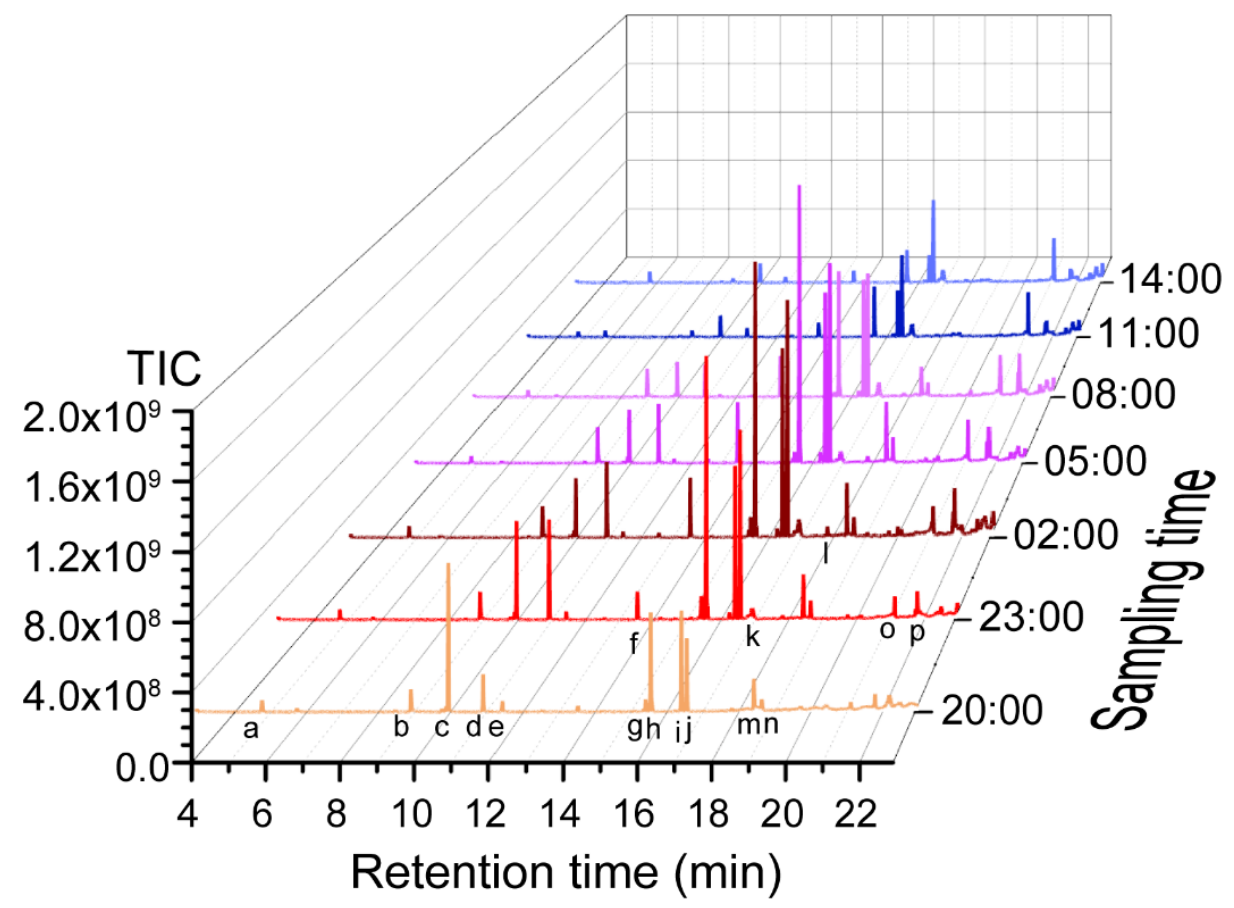

Figure 1. Floral volatile profiling during flowering lifetime. J. sambac flowers were sampled at a $3 \mathrm{~h}$ interval after opening at the evening and the methanol extracts of petals were subjected to GC-MS analysis. The experiment was conducted using at least three sets of samples representing 24 pots of plants. Shown here is one set of results. Except for benzyl alcohol (RT $8.89 \mathrm{~min}$, b), linalool (RT $9.93 \mathrm{~min}, \mathrm{c}$ ), benzyl acetate (RT $10.90 \mathrm{~min}, \mathrm{~d}$ ), and $\alpha$-farnesene (RT $15.55 \mathrm{~min}, \mathrm{~h}$ ), peaks were tentatively identified based on RI and mass spectrum (see Figure S1): a, 3-hexenal; b, benzyl alcohol; c, linalool; $d$, benzyl acetate; e, methyl salicylate; $f$, methyl anthranilate; $g$, germacrene $D ; h, \alpha$-farnesene; $\mathrm{i}$, cis-hexenyl benzoate; $\mathrm{j}$, germacrene D-4-ol; k, 1-docosene; l, unknow; m, benzoic acid-2-propenyl ester; $\mathrm{n}$, benzyl benzoate; $\mathrm{o}$, nerolidol; $\mathrm{p}$, methyl linolenate.

Table 1. Major floral volatile benzenoids/phenylpropanoids in J. sambac petal extracts post anthesis.

\begin{tabular}{|c|c|c|c|c|c|c|c|}
\hline \multirow[b]{2}{*}{ Time } & \multirow[b]{2}{*}{ 3-Hexenal } & \multicolumn{5}{|c|}{ Concentration $\left(\mathrm{mg} \mathrm{g}^{-1} \mathrm{FW}\right) *$} & \multirow{2}{*}{$\begin{array}{c}\text { Benzoic } \\
\text { Acid-2-Propenyl } \\
\text { Ester }\end{array}$} \\
\hline & & $\begin{array}{c}\text { Benzyl } \\
\text { Alcohol }\end{array}$ & $\begin{array}{l}\text { Benzyl } \\
\text { Acetate }\end{array}$ & $\begin{array}{c}\text { Methyl } \\
\text { Anthranilate }\end{array}$ & $\begin{array}{l}\text { cis-3-Hexenyl } \\
\text { Benzoate }\end{array}$ & $\begin{array}{c}\text { Benzyl } \\
\text { Benzoate }\end{array}$ & \\
\hline 20:00 & $16.5 \pm 1.5 \mathrm{a}$ & $41.3 \pm 2.3 c$ & $34.2 \pm 1.7 \mathrm{e}$ & $10.7 \pm 0.6 \mathrm{f}$ & $140.8 \pm 1.3 \mathrm{~d}$ & $14.3 \pm 0.2 \mathrm{e}$ & $50.4 \pm 8.4 c$ \\
\hline 23:00 & $15.3 \pm 0.9 \mathrm{a}$ & $48.3 \pm 3.5 b$ & $199.4 \pm 11.3 b$ & $50.1 \pm 3.1 \mathrm{~d}$ & $208.9 \pm 13.3 \mathrm{a}$ & $23.9 \pm 1.0 \mathrm{c}$ & $69.0 \pm 7.04 b$ \\
\hline 02:00 & $14.2 \pm 1.1 \mathrm{a}$ & $48.3 \pm 3.2 b$ & $227.2 \pm 10.0 \mathrm{a}$ & $87.2 \pm 1.7 \mathrm{~b}$ & $228.2 \pm 7.8 \mathrm{a}$ & $25.2 \pm 0.62 b$ & $77.6 \pm 2.5 \mathrm{a}$ \\
\hline 05:00 & $10.9 \pm 0.6 c$ & $55.4 \pm 3.4 \mathrm{a}$ & $148.8 \pm 5.9 c$ & $95.4 \pm 3.4 \mathrm{a}$ & $170.2 \pm 8.2 \mathrm{~b}$ & $29.7 \pm 1.1 \mathrm{a}$ & $80.9 \pm 2.0 \mathrm{a}$ \\
\hline 08:00 & $11.1 \pm 0.7 \mathrm{bc}$ & $52.6 \pm 1.2 \mathrm{a}$ & $75.9 \pm 1.3 \mathrm{~d}$ & $62.9 \pm 2.9 c$ & $134.8 \pm 2.5 c$ & $19.8 \pm 0.6 \mathrm{~d}$ & $42.5 \pm 0.6 \mathrm{~d}$ \\
\hline $11: 00$ & $12.5 \pm 1.1 \mathrm{~b}$ & $42.8 \pm 0.3 c$ & $33.4 \pm 0.8 \mathrm{ef}$ & $47.9 \pm 1.1 \mathrm{~d}$ & $68.7 \pm 2.1 \mathrm{~d}$ & $10.1 \pm 0.2 \mathrm{fg}$ & $6.5 \pm 0.2 \mathrm{e}$ \\
\hline $14: 00$ & $7.7 \pm 1.3 \mathrm{~d}$ & $15.2 \pm 1.2 \mathrm{~d}$ & $27.8 \pm 0.5 \mathrm{fg}$ & $26.6 \pm 1.2 \mathrm{e}$ & $44.5 \pm 3.6 \mathrm{e}$ & $8.9 \pm 0.8 \mathrm{~g}$ & $8.2 \pm 1.0 \mathrm{e}$ \\
\hline $17: 00$ & $2.3 \pm 0.4 \mathrm{e}$ & $9.0 \pm 0.2 \mathrm{e}$ & $24.1 \pm 0.8 \mathrm{~g}$ & $23.1 \pm 1.7 \mathrm{e}$ & $13.8 \pm 0.7 \mathrm{f}$ & $11.2 \pm 1.1 \mathrm{f}$ & $7.5 \pm 0.8 \mathrm{e}$ \\
\hline
\end{tabular}

* Relative to an internal standard isobutylbenzene. Means \pm SD followed by same letter indicates no significant difference within each column $(p<0.05, \mathrm{n}=3)$.

\subsection{Cloning of Petal-Specific BAHD-Like cDNAs}

We sought to identify the benzyl alcohol acyltransferase genes that were specifically expressed in the petal. By BLAST searching the floral transcriptome [22] using sequences of known proteins from C. breweri [23], P. hybrida [24], and Populus trichocarpa [25] as the query, we found at least 18 homologous EST sequences expressed in the petal (Figure S2). After removing shorter $(<500 \mathrm{bp})$ or redundant sequences, the unigenes were matched to full-length cDNAs in a lab-generated PacBio SMRT long-read transcriptome dataset via BLAST search, finally yielding seven unique BAHD-like homologs (Figure S2). These genes were designed as JSBEAT1 through seven and the deduced amino acid sequences 
were used to align with known enzymes from other species (Figure S3). The JsBEAT1-, 2-, $4-$, and 5-encoded proteins belong to the Clade V, whereas JsBEAT3 and 6 code for Clade IV enzymes, and the JsBEAT7 protein clusters into Clade III (Figure S3). The two conserved motifs HXXXD and DFGWG of BAHD acyltransferases are presented in the seven JsBEAT proteins, although the DFGWG motif in JsBEAT3 and 6 have a substituted Cys and Gly for the Trp, respectively. Moreover, the negative Asp residue at the DFGWG motif in JsBEAT2 is replaced by a highly polar Asn (Figure S4).

We further determined the transcript abundance of the seven JsBEAT genes in the opening petal and in different tissues using quantitative RT-PCR. In the petal, the expression of $J s B E A T 1,4,6$, and 7 peaked earlier at night, with the maximum at about 23:00 $\mathrm{h}$, while JsBEAT2, 3, and 5 showed delayed expression peaks by $\sim 3-6 \mathrm{~h}$ (Figure 2A). Among the genes, JsBEAT2 and 1 were the most expressed and their transcript levels were approximately $7-11$ folds of that of the moderately expressed JsBEAT4 and 5 (Figure 2B). The other three genes, JsBEAT3, 6 and 7 were expressed with minimum or hardly detectable level in all tissues tested (Figure 2). Interestingly, JsBEAT1 was also the most expressed among the seven genes in stems and leaves, though at a relatively lower level (Figure 2B). It seems that the petals of J. sambac mainly express the Clade V BAHD acyltransferase genes, JsBEAT1, 2, 4 , and 5 .

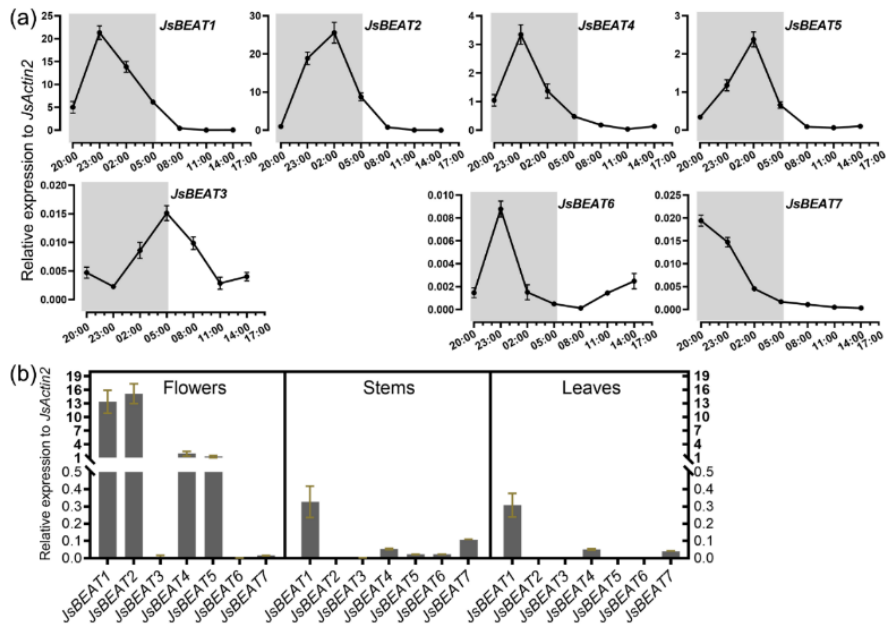

Figure 2. Expression profiles of seven floral-specific BAHD-like genes detected via quantitative RT-PCR. (a) Time-resolved transcript level in petals post anthesis. Shaded area indicates the night period; (b) transcript abundance in the tissues. The flower samples were taken at 21:00 h. The error bars represent SD of three biological replications (sets of 10 flowers from 5 different plants). Each qRT-PCR reaction consisted of at least 3 technical repeats.

The subcellular localization of the two highly expressed JsBEAT1 and JsBEAT2 were also monitored using C-terminal GFP-tagged fusion transiently expressed in J. sambac petal protoplasts and in the leaf epidermis of $N$. benthamiana. It could be observed that both were localized to the cytosol (Figure S5). In addition, the JsBEAT1-GFP also exhibited strong fluorescent signals in the nucleus whereas the JsBEAT2-GFP displayed obvious localization in unknown intracellular structures, as seen much more in the heterologously expressing leaves (Figure S5). These results were roughly consistent with the predicted subcellular localization by three different programs (Table S1). The pIs of JsBEAT1 and JsBEAT2 proteins were predicted as 7.69 and 7.61, respectively. Given a normal $\mathrm{pH}$ of $\sim 7.0-7.2$ in the cytosol, both proteins would be positively charged when residing in the cytoplasm.

\subsection{Enzymatic Characterization of the Recombinant JsBEAT1 and JsBEAT2}

We then expressed the full-length cDNAs in E. coli to obtain purified recombinant proteins, using a N-terminal fusion of $6 x H i s-t a g$ or a GST-tag. The recombinant $6 x H i s-$ 
JsBEAT2 was readily generated; however, the JsBEAT1 was only successfully produced as a GST-tagged fusion (Figure S6).

Although purified recombinant proteins contained either the 6xHis-or the GST-tag at the N-termina, they did show catalytic activities converting the substrates benzyl alcohol and acetyl-CoA to benzyl acetate in a preliminary experiment. Thus, the recombinant proteins were used in serial reactions with different substrate concentrations to determine the enzymatic property.

Using $300 \mu \mathrm{M}$ acetyl-CoA as the acyl doner, the apparent $V$ max and $\mathrm{Km}$ of the GSTJsBEAT1 for substrate benzyl alcohol were estimated as $12.4 \pm 1.2 \mathrm{nmol} \mathrm{mg}^{-1}$ protein $\min ^{-1}$ and $447.3 \pm 107.8 \mu \mathrm{M}$, respectively. At a fixed $300 \mu \mathrm{M}$ benzyl alcohol as the acceptor, the estimated apparent $V$ max and $K \mathrm{~m}$ of the GST-JsBEAT1 against the acetyl-CoA was $18.1 \pm 1.6 \mathrm{nmol} \mathrm{mg}^{-1}$ protein $\min ^{-1}$ and $546.0 \pm 94.5 \mu \mathrm{M}$, respectively (Figure 3). Using $1 \mu \mathrm{M}$ fixed concentrations of substrates, similar results were obtained. Under these conditions, we calculated the turnover number Kcat of the GST-JsBEAT1 as $201.5 \pm 4.1 \mathrm{~s}^{-1}$ benzyl alcohol or $316.8 \pm 4.4 \mathrm{~s}^{-1}$ acetyl-CoA.
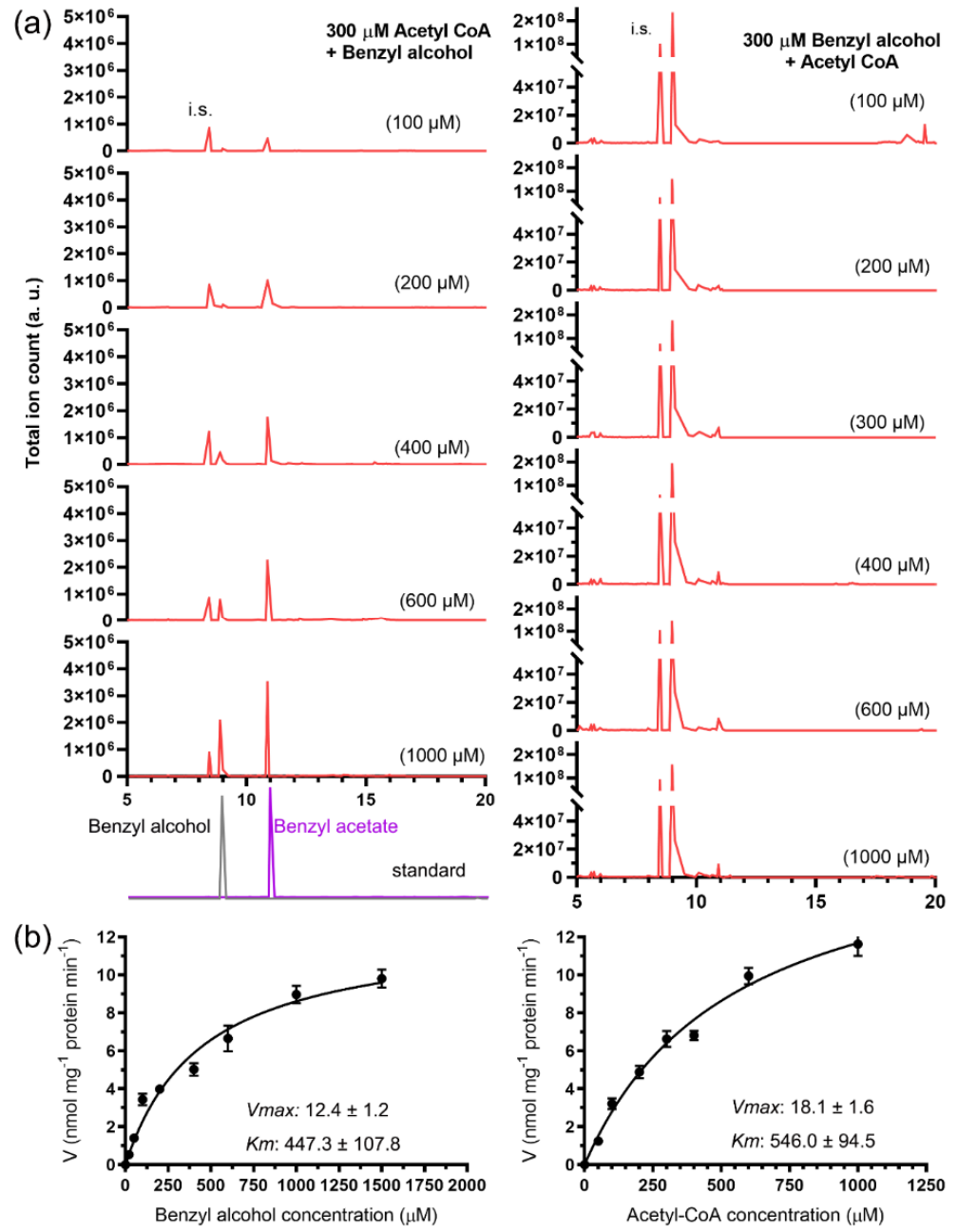

Figure 3. The recombinant GST-JsBEAT1 catalyzed the in vitro formation of benzyl acetate from benzyl alcohol and acetyl-CoA. (a) Representative chromograms of the reaction products; (b) curve fitting against the two substrates, $R^{2}=0.97$ and 0.99 , respectively. The experiments were repeated at least three times using three sets of recombinant proteins.

The recombinant $6 \times$ His-JsBEAT2 showed slightly higher activities to catalyze the formation of benzyl acetate than the GST-JsBEAT1. Its $V_{\max }$ and $K_{\mathrm{m}}$ for the substrate benzyl alcohol were $25.8 \pm 0.8 \mathrm{nmol} \mathrm{mg}^{-1}$ protein $\mathrm{min}^{-1}$ and $278.7 \pm 26.5 \mu \mathrm{M}$, respectively. For the substrate acetyl-CoA, a $V_{\max }$ of $23.0 \pm 1.0 \mathrm{nmol} \mathrm{mg}^{-1}$ protein $\mathrm{min}^{-1}$ and a $K_{\mathrm{m}}$ 
of $317.3 \pm 31.7 \mu \mathrm{M}$ were estimated (Figure 4 ). However, the $6 x$ His-JsBEAT2 had a lower $k_{\text {cat }}$ for benzyl alcohol $\left(36.8 \pm 0.6 \mathrm{~s}^{-1}\right)$ and for acetyl-CoA $\left(25.7 \pm 0.4 \mathrm{~s}^{-1}\right)$ as well as the GST-JsBEAT1.

(a)

$$
\begin{aligned}
& 1 \mathrm{mM} \text { Acetyl CoA } \\
& + \text { Benzyl alcohol }
\end{aligned}
$$
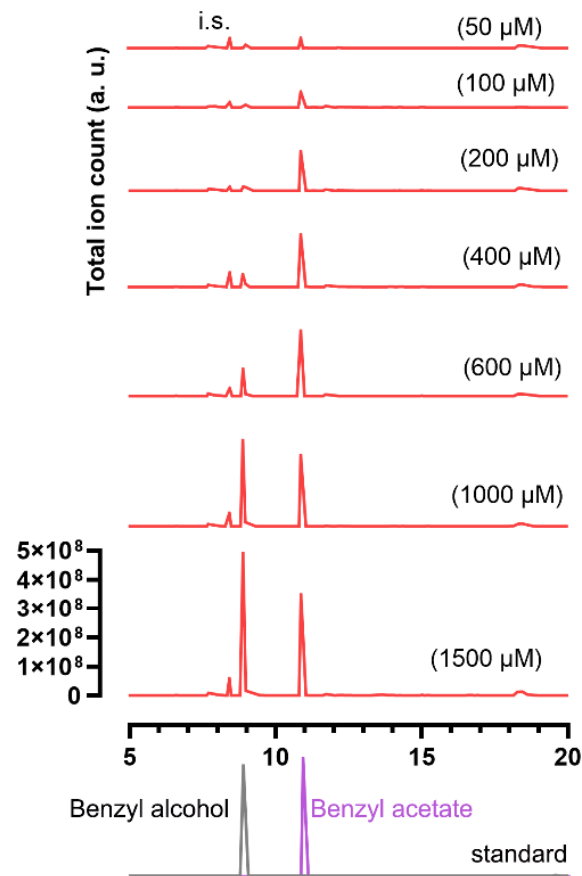

(b)

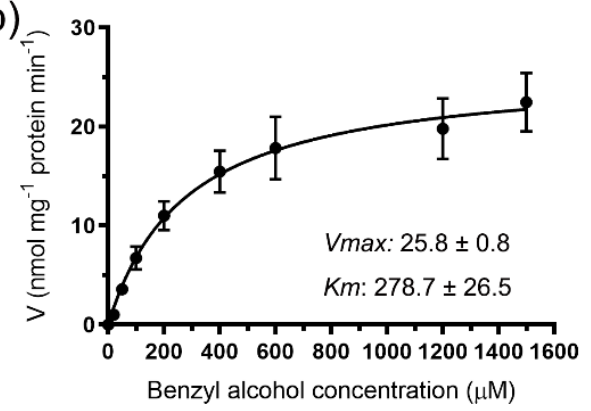

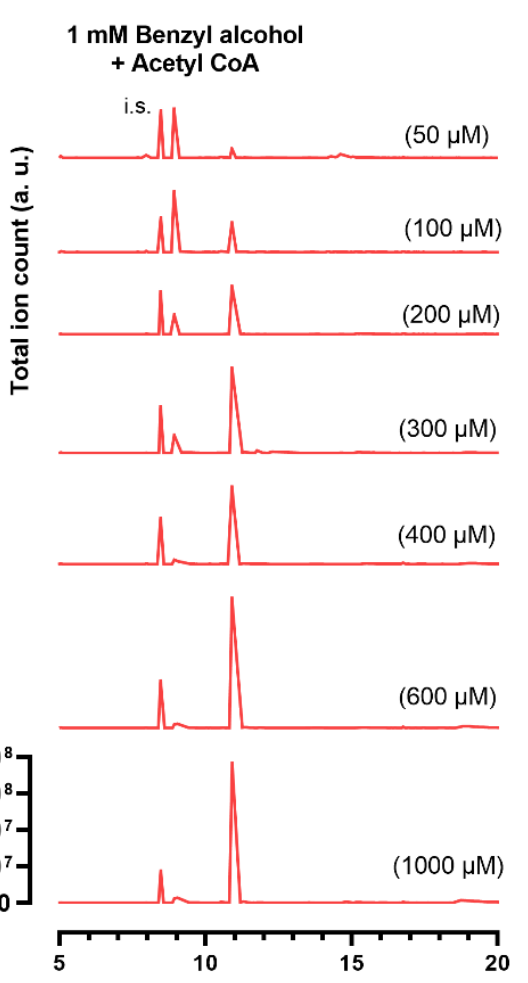

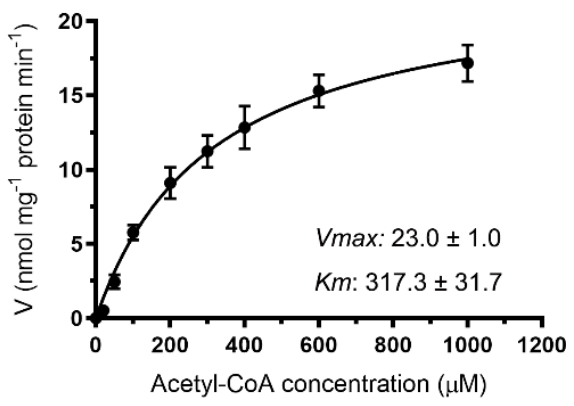

Figure 4. The recombinant 6xHis-JsBEAT2 catalyzed the in vitro formation of benzyl acetate from benzyl alcohol and acetyl-CoA. (a) Representative chromograms of the reaction products; (b) curve fitting against the two substrates, $R^{2}=0.99$ and 0.99 , respectively. The experiments were repeated at least three times using three sets of recombinant proteins.

Taken together, these in vitro assays indicated that both JsBEAT1 and JsBEAT2 were able to catalyze the acryl transfer from acetyl-CoA to benzyl alcohol and produce benzyl acetate. By comparison, JsBEAT2 seemed to be slightly higher in affinity to both substrates since its $K_{\mathrm{m}}$ values for both were lower by a factor of $\sim 0.6$. However, the enzyme reaction by JsBEAT1 was more efficient (Table 2). 
Table 2. Steady-state kinetic parameters of JsBEAT1 and JsBEAT2 summarized from Figures 4 and 5.

\begin{tabular}{|c|c|c|c|c|}
\hline & & $\begin{array}{l}K_{\mathrm{m}} \\
\mu \mathrm{M}\end{array}$ & $\begin{array}{l}k_{\text {cat }} \\
\mathrm{s}^{-1}\end{array}$ & $\begin{array}{c}k_{\mathrm{cat}} / K_{\mathrm{m}} \\
\mathrm{nM}^{-1} \mathrm{~s}^{-1}\end{array}$ \\
\hline \multirow{2}{*}{ GST-JsBEAT1 } & $\begin{array}{c}\text { Benzyl alcohol } \\
\text { (with acetyl-CoA) }\end{array}$ & $447.3 \pm 107.8$ & $201.5 \pm 4.1$ & $450.5 \pm 241.8$ \\
\hline & $\begin{array}{c}\text { Acetyl-CoA } \\
\text { (with benzyl alcohol) }\end{array}$ & $546.0 \pm 94.5$ & $316.8 \pm 4.4$ & $580.2 \pm 173.6$ \\
\hline \multirow{2}{*}{ 6xHis-JsBEAT2 } & $\begin{array}{c}\text { Benzyl alcohol } \\
\text { (with acetyl-CoA) }\end{array}$ & $278.7 \pm 26.5$ & $36.8 \pm 0.6$ & $132.0 \pm 96.5$ \\
\hline & $\begin{array}{c}\text { Acetyl-CoA } \\
\text { (with benzyl alcohol) }\end{array}$ & $317.3 \pm 31.7$ & $25.7 \pm 0.4$ & $81.0 \pm 67.4$ \\
\hline
\end{tabular}
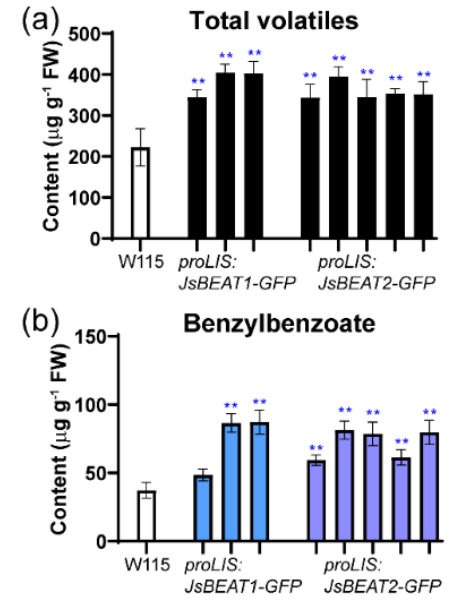

(c)

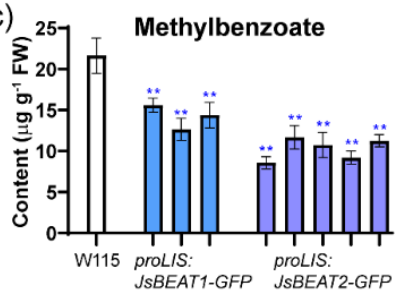

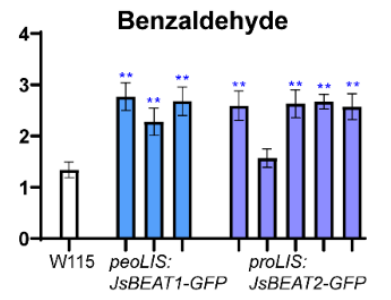

Benzyl acetate
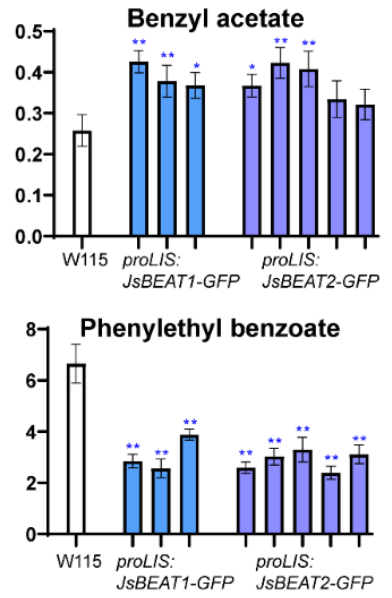
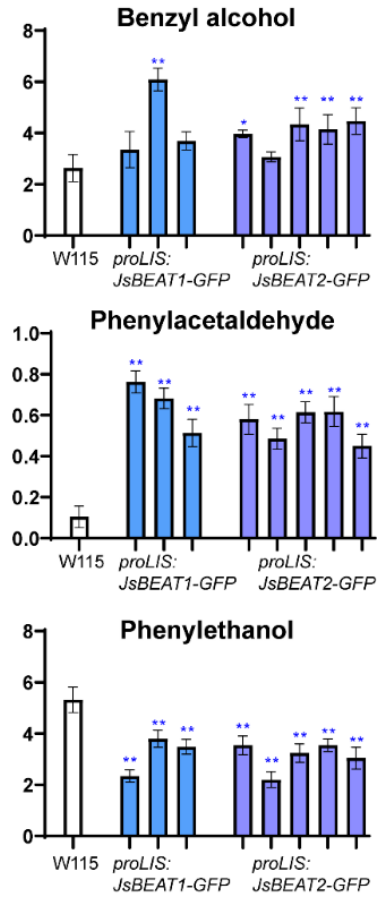

Figure 5. Floral expression of JsBEAT1 and JsBEAT2 in transgenic P. hybrida W115 enhances major benzenoid volatile production but decreased methyl benzoate and phenylethyl benzoate. (a) and (b) show the increased compounds and the total amount of compounds, while (c) shows the reduced compounds. The quantification is relative to an internal standard isobutylbenzene. Error bars represent SD of three independent assays on pooled samples from 5-7 flower. Significant level: ${ }^{*} p<0.05 ;{ }^{* *} p<0.01$ confirmed by Student's $t$-test.

\subsection{Ectopic Expression of JsBEAT1 and JsBEAT2 in Flowers of Transgenic Petunia hybrida Induced More Benzylbenzoate and Benzylacetate}

To assess the function of the two JsBEAT enzymes in planta, we generated transgenic plants ectopically expressing JsBEAT1 and JsBEAT2 in P. hybrida 'Mitchell Diploid' (W115) because an attempt to transform J. sambac had not been successful. The JsBEATs were expressed as a GFP fusion driven by $1 \mathrm{~Kb}$ promoter fragment of the flower-specific C. breweri linalool synthase (LIS) [26,27]. We obtained T2 transgenic plants by subsequent screening of seed germination on kanamycin-containing medium. The transgenic plants showed normal flowering phenotype but developed slightly more flowers per plant (Figure S7a). The T-DNA insertion was verified by using PCR amplification (Figure S7b), and the mRNA level of the transgenes was measured as one order of magnitude over the wild-type W115 background via qRT-PCR with most independent lines (Figure S7c). The expression of the fusion proteins was further confirmed by Western blotting using an anti-GFP antibody (Figure S7d). In addition, we also observed the GFP fluorescent signal in the epidermic 
cells of the corolla from transgenic plants, which showed localization to some unknown granule subcellular structures and was different to those observed above in the transiently transfected J. sambac petal protoplasts and the N. benthamiana leaves (Figure S7e).

The flowers of the P. hybrida W115 emit mainly benzenoid and phenylpropanoid volatiles derived from three metabolic pathways of phenylalanine [24,28-30]. Using hexanol extraction, we determined the volatile compounds in the petals of the W115 and the transgenic plants via a GC-MS (Figure S8). The compounds were tentatively identified based on their Kovats retention index (RI) and MS spectrum comparison with known compounds in the NIST MS database (Figure S9).

Quantification of the relative abundance of the volatile compounds indicated that major benzenoid and phenylpropanoid production in the flower was enhanced by the ectopic expression of both JsBEAT genes. The total content of volatiles in the corolla was increased by a factor of 1.5-1.9 compared to that in the W115 (Figure 5a). Notably, bezylbenzoate, the most abundant component of the floral volatiles, increased by almost 2 -folds in most transgenic lines, while the minor compound benzylacetate by about $50 \%$ (Figure 5b). However, concentration of the other two benzoate acryl esters, methylbenzoate and phenylethylbenzoate, were declined to approximately one-half of that in the W115 (Figure 5c). Other volatiles, such as benzaldehyde, benzylalcohol, and phenylacetaldehyde were also accumulated in the transgenic flowers, whereas phenylethanol was reduced (Figure 5). Overall, no obvious phenotypical difference between the two transgenes was observed, and the overexpression of both genes significantly enhanced the synthetic flux to benzylbenzoate and benzylacetate, as well as a concomitant rise in benzylalcohol and benzaldehyde (Figure 6).

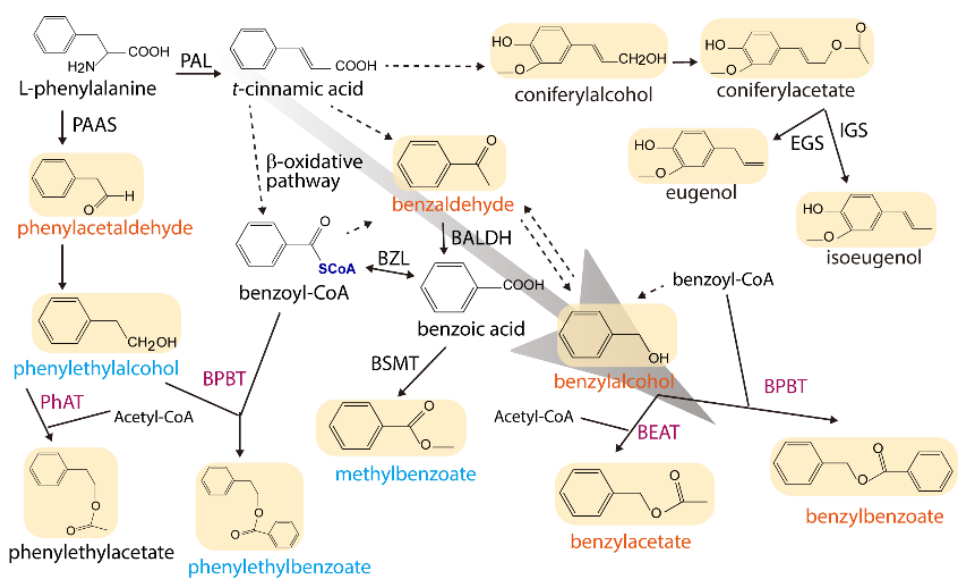

Figure 6. A simplified metabolic network for major floral volatile benzenoid/phenylpropanoid compounds in P. hybrida W115, depicting the effects of ectopic expression of the two JsBEATs. The volatile compounds are shades and the names in tangerine orange, cyan blue, and black indicate the compound is increased, decreased and no change or not detected, respectively. Solid arrow indicates a described conversion while a broken arrow denotes multiple steps and/or uncharacterized reactions. Enzyme abbreviations: BALDH, benzaldehyde dehydrogenase; BEAT, benzylalcohol acetyl-CoA acetyltransferase; BPBT, benzylalcohol/phenylethanol benzoyl-CoA benzoyltransferase; BSMT, benzoic acid/salicylic acid carboxyl methyltransferase; BZL, benzoate:CoA ligase; EGS, eugenol synthase; IGS, isoeugenol synthase; PAAS, phenylacetaldehyde synthase; PAL, phenylalanine ammonia lyase; PhAT, phenylalcohol acetyl-CoA acetyltransferase. Enzymes in violet are members of the BAHD acyltransferase family. The background gray arrow highlights the volatile flux driven by the overexpression.

\section{Discussion}

After blooming at night, J. sambac flowers produce and emit various volatile benzenoid compounds among others, with benzylacetate occupying one-third to one-half of headspace volatiles and $\sim 10$ to $30 \%$ in the extracts (Table 1 ) $[8,9,14]$. In this study, we have 
identified at least four candidate BAHD acyltransferase-coding genes that were expressed preferentially at similar time window (Figure 2 and Figures S2-S4). Two highly expressed JsBEAT1 and JsBEAT2 were full-length cDNA cloned, and the encoded proteins could convert benzyl-alcohol to benzylacetate by using acetyl-CoA as the acyl donor in vitro. In addition, JSBEAT4 and 5 were also moderately expressed (having a transcript abundance of $\sim$ one-seventh of JsBEAT1 and 2). Since we did not characterize these two genes, it could not be excluded that these two might also contribute to the formation of benzylacetate in the J. sambac flowers. Although not tested, both JsBEAT1 and JsBEAT2 may also be capable of making other minor acetylated scent compounds found in the J. sambac flowers, in addition to benzylacetate. The question remains as to what extent may individual JsBEAT contribute to the floral benzenoids production, which requires further experiments using gene knockout or other approaches.

At the amino acid level, JsBEAT1 shares a $48.86,28.24$, and $25.89 \%$ identity with JsBEAT4, JsBEAT2, and JsBEAT5, respectively, while JsBEAT2 is 27.40 to $32.22 \%$ identical to JsBEAT4 and JsBEAT5. Phylogenetically, the four petal-expressing acyltransferases are grouped into the clade V of the BAHD family (Figure S3). This clade includes some previously described members such as the benzyl alcohol/phenylethanol benzoyl-CoA benzoyltransferases (BPBT) from P. hybrida and C. breweri flowers and leaves, which are responsible for volatile benzenoids production via the $\beta$-oxidative benylbenzoate synthetic pathway $[23,24]$. Another example comes from the Concord grape; the VIAMAT catalyzes the formation of methyl anthranilate from anthraniloyl-CoA and methanol in the berry [31]. Additionally, other reported BAHD-clade $\mathrm{V}$ acyltransferases catalyze the formation of $\mathrm{O}$ - or $\mathrm{N}$-acylation on diverse substrates with different acyl-CoA donors, and may be involved in defense against herbivores, UV-protection, and pathogen resistance, as well as in cell-wall biosynthesis $[15,19]$. Our results showed that the two JsBEAT could equally enhance the floral benzenoid volatile production, especially the accumulation of benzylbenzoate and benzylacetate (Figure 6) in the transgenic $P$. hybrida plants, suggesting that they may be functionally redundant in the $J$. sambac flowers. Or else they may possess a subtle, not-yetdetermined catalytic preference depending on the substrate availability and subcellular compartmentalization. Indeed, the subcellular localizations of both JsBEAT1 and 2 in transgenic P. hybrida were found unexpectedly in granule cytosolic structures (Figure S6e), other than in the bulk cytoplasm [19] as seen in Jasminum petal protoplasts (Figure S5). The nature of the observed cellular granule structures is not known; however, peroxisomes or mitochondria or membrane vesicles are considered as possible candidates, as such the two enzymes may be recruited by specific unknown proteins from the heterologous $P$. hybrida flower tissue. These possibilities require further investigation.

The apparent $\mathrm{Km}$ for both acyl donor (acetyl-CoA, ranging from 317.3 to $546.0 \mu \mathrm{M}$ ) and acyl acceptor (benzyl alcohol, ranging from 278.7 to $447.3 \mu \mathrm{M}$ ) are rather high in our enzymatic assay using GST-tagged or $10 \times$ His-tagged proteins, as compared to the canonical CbBEAT, CbBEBT and CbCHAT [23,32], indicating that both acetyl-CoA and benzyl alcohol may not be the preferred substrates for the two JsBEATs. The apparent $\mathrm{Km}$ for a preferred substrate in many plant BAHDs is reported ranging from several to two hundred $\mu \mathrm{M}([33,34])$. However, some BAHDs may exhibit higher $K m(>300 \mu \mathrm{M}$ for the preferred substrates) [35]. Thus, it will be necessary to further test the enzymatic activity of the two JsBEAT using different donor or acceptor substrates to determine the preferent substrates.

In summary, two highly expressed BAHD acyltransferases, capable of acylating benzylalcohol and other alcohol compounds, are likely responsible for the volatile benzenoid production in the nigh blooming fragrant flowers of J. sambac, with somewhat functional redundance. 


\section{Materials and Methods}

\subsection{Plants and Culture Conditions}

Four-year-old J. sambac (L.) Aiton cv 'shuangban' plants were propagated from cuttings and maintained in the greenhouse. Plants were transferred to $30 \mathrm{~cm}$ containers in a climate room 6 months before the experiments, where the plants received LED illumination at $\sim 245 \mu \mathrm{mol} \mathrm{m} \mathrm{m}^{-2} \mathrm{~s}^{-1}$ with a day/night regime of $16 / 8 \mathrm{~h}$. The climate room was configured at a day/night temperature of $28 / 22{ }^{\circ} \mathrm{C}$ and a constant humidity of $70 \%$. P. hybrida 'Mitchell Diploid' (W115) was seed propagated and grown in a climate room under similar conditions.

\subsection{Volatile Extration and GC-MS Determination}

Labeled flowers of $J$. sambac plants were collected at consecutive time points from fresh opening throughout senescence, starting at 20:00 h of the first day. The petals were separated, weighed, frozen in liquid nitrogen, and grounded into fine powders. About $400 \mathrm{mg}$ powders were extracted with hexane (cat. Nr. H100107, Aladdin, Shanghai, China) and $1.11 \mu \mathrm{g} \mathrm{mL}^{-1}$ isobutylbenzene (cat. Nr. 113166, Merck, Darmstadt, Germany) was spike-in as an internal standard. After $3 \mathrm{~h}$ incubation at room temperature (RT) with rotation at $150 \mathrm{rpm}$, the supernatant was collected by centrifugation at $1300 \mathrm{rpm}$ for $10 \mathrm{~min}$ and filtered through a $0.22 \mu \mathrm{m}$ membrane (Merck, Darmstadt, Germany). The clear extracts were used for GC injections and 5 injections were conducted for each extract. Usually, 5 to 10 flowers from 9 plants were collected and pooled as one biological sample, which were repeated in three replications. After flowering, the plants were subjected to light pruning. The experiment was repeated once in the next flowering flush.

Sampling of P. hybrida W115 flowers was performed at 23:00 h of day 2 and 3 post opening when the emission was peaked [36]. Pooled corolla was used for hexane extraction as mentioned above.

A PerkinElmer Clarus 680 GC equipped with a SQ8 TGC/MS detector and an Agilent J\&W HP-5MS capillary column ( $0.25 \mathrm{~mm}$ diameter, $30 \mathrm{~m}$ length, and $0.25 \mu \mathrm{m}$ film thickness) was employed for the GC-MS analysis. Oven temperature program was set as: started at $40{ }^{\circ} \mathrm{C}$ for $2 \mathrm{~min}$, then raised at $10^{\circ} \mathrm{C} \mathrm{min}^{-1}$ to $250{ }^{\circ} \mathrm{C}$. The MS interface temperature (split injection) was $280{ }^{\circ} \mathrm{C}$. MS EI scan range was 40 to $500 \mathrm{~m} / \mathrm{z}$. Peaks were calibrated using $n$-hydrocarbons (C8-C25, Sigma, Saint Louis, MO, USA) to convert the retention time of each component to Kovats Retention Index (RI) under the same conditions.

Volatile compounds were putatively identified based on their RI and MS spectra compared to those in the NIST11 MS library and when available, verified by authentic reference substances. To quantify the concentration of the compounds, the peak area was compared to an internal standard and calibrated further by using curves made with authentic references or closet hydrocarbons.

\subsection{RNA Isolation, Real-Time RT-PCR, Full-Length cDNA Cloning, and Vector Construction}

Total RNA was isolated using a TransZol Up Plus RNA Kit (TransGen Biotech, Shanghai, China). Synthesis of cDNA was conducted in a $20 \mu \mathrm{L}$ reaction containing Oligo $\mathrm{d}(\mathrm{T}) 18$ primers and the transcript ${ }^{\circledR} \mathrm{RT} / \mathrm{RI}$ Enzyme Transcriptase (TransGen Biotech) using approximately $1 \mu \mathrm{g}$ total RNA as templates.

Real-time RT-PCR was run on a LightCycler 96 (Roche Molecular Systems, Inc., Pleasanton, CA, USA) and each $20 \mu \mathrm{L}$ reaction contained $1 \mu \mathrm{L}$ cDNA, $10 \mu \mathrm{L}$ of $2 \times$ TransStart $^{\circledR}$ Green qPCR SuperMix (TransGen Biotech, Shanghai, China), and $0.2 \mu \mathrm{M}$ of each primer pair (Table S2). We verified the specificity and amplification efficiency of all primer pairs by using melt curves and five-point calibration of ten-fold serial dilutions. Quantification of each gene expression was determined at least by three technical repeats and three biological replications using two reference genes, JsACTIN2 and JsUBQ10, which yielded comparable results.

The full-length JsBEAT1 and JsBEAT2 cDNA were PCR amplified using designed primers (Table S2) and cloned into the GATEWAY pENTR/D-TOPO vector, respectively. 
Subcloning into the binary vector pK7FWG2.0 [37] was achieved by using the LR reaction of the respective $\mathrm{pENTR/D-TOPO}$ plasmid harboring the respective JsBEAT. The generated pK7-JsBEAT1 and pK7-JsBEAT2 were used for PEG-mediated protoplast transformation and Agrobacterium tumefaciens mediated leaf infiltration. These two vectors utilized the Cauliflower Mosaic Virus 35S promoter to drive the expression.

To construct a floral-specific version of binary vector, we first synthesized a $1031 \mathrm{bp}$ fragment of the $5^{\prime}$-sequence of the C. breweri LIS gene [27] with incorporated HindIII/XhoI restriction sites (Gene Synthesis, Invitrogen, Shanghai, China), and the fragment was subcloned to replace the 35S promoter in the pK7FWG2.0, yielding the proLIS-pK7FWG. Subsequently, LR reaction was conducted to make the proLIS-JsBEAT1-GFP and proLISJsBEAT2-GFP binary vectors, using the proLIS-pK7FWG and the respective pENTR/DTOPO vectors harboring either JsBEAT1 or JsBEAT2 cDNA. These proLIS-driven expression vectors were used in transformation of P.hybrida W115.

All cloned sequences and constructs were verified by Sanger sequencing.

To generate sequence alignment and phylogenetic tree, the deduced amino acid sequences of JsBEATs and those of selected plant BAHD proteins previously characterized $[15,19]$ were aligned by using Web-based Clustal and MAFFT programs with default parameters [38,39]. The MEGA X ver. 10.2 .6 was used to analyze the phylogenetic relationship and to generate a Neighbor-Joining tree.

\subsection{Recombinant Proteins and In Vitro Enzyme Reaction}

The JsBEAT2 cDNA were PCR amplified and subcloned into the pQE30 (QIAGEN) vectors, using Bam $\mathrm{HI} /$ PstI restriction sites. The resulting plasmid was introduced into an $E$. coli M15 strain, and the transformant was grown to an $0.6 \mathrm{OD}_{600}$ before induction of protein expression. The recombinant JsBEAT2 was best achieved by adding $0.4 \mathrm{mM}$ isopropyl $\beta$-D-1-thiogalactopyranoside isopropyl $\beta$-d-1-thiogalactopyranoside (IPTG) and incubated for $10 \mathrm{~h}$ at $25^{\circ} \mathrm{C}$. Purification of the N-terminal-6xHis-tagged recombinant JsBEAT2 was carried out by using a Ni-NTA column kit (Sangon, Shanghai, China), with an elution buffer containing $80 \mathrm{mM}$ imidazole.

Since JsBEAT1 was not expressed well in the pQE30/M15 system, we reconstructed a pEGX-4T-1 (GE Healthcare) vector harboring the JsBEAT1 cDNA at the BamHI/NotI cloning sites. The E. coli Rosetta strain was used to express the N-terminal-GST-tagged JsBEAT1 protein. Culture of the recombinant Rosetta cells at an $0.6 \mathrm{OD}_{600}$ was incubated for $16 \mathrm{~h}$ at $25^{\circ} \mathrm{C}$ under $0.4 \mathrm{mM}$ IPTG to induce protein synthesis. Cell lysates were loaded on a GST4FF prepacked gravity column (Sangon, Shanghai, China), and the recombinant GST-JsBEAT1 was eluted with $30 \mathrm{mM}$ glutathione-containing buffer.

All constructs were verified by sequencing, and protein concentration after purification was monitored via the Quick Start Bradford protein assay kits using bovine serum albumin as a standard (Bio-Rad). The expected size of the recombinant fusion proteins was checked by SDS-PAGE (Figure S5).

The enzyme activity was determined in a $320 \mu \mathrm{L}$ reaction mixture consisting of $250 \mathrm{mM}$ Tri- $\mathrm{HCl}$ (pH 7.5), $25 \mathrm{mM}$ each of $\mathrm{MgCl}_{2}$ and $\mathrm{KCl}, 10 \mathrm{mM} \beta$-mercaptoethanol, and $30 \mu \mathrm{g}$ GST-JsBEAT1 or $200 \mu \mathrm{g} 6$ xHis-JsBEAT2 proteins, supplemented with varied concentrations of substrates (benzylalcohol and acetyl-CoA). The reaction was allowed for $1 \mathrm{~h}$ at $30{ }^{\circ} \mathrm{C}$ and terminated by mixing with an equal volume of hexane containing $0.2 \mathrm{mM}$ isobutylbenzene as an internal standard. The reaction mixture was filtered through a $0.22 \mu \mathrm{m}$ membrane and subjected to GC-MS analysis. The optimization of the reaction conditions for $\mathrm{pH}$ and temperature were predetermined by using a set of appropriate buffers from $\mathrm{pH} 6.0$ to 8.0 and by testing a range of 20 to $35{ }^{\circ} \mathrm{C}$, with $1 \mathrm{mM}$ acetyl-CoA/benzylalcohol as the substrates. All assays were performed in triplicate.

If not specific, all chemicals were purchased from Sigma-Aldrich. 


\subsection{Transient Expression and Stable Transformation}

Protoplast isolation and PEG-mediated transfection using fresh J. sambac petals had been described previously [22]. The pK7-JsBEAT1 and pK7-JsBEAT2 vectors (Section 4.3) expressing C-terminus GFP-tagged proteins, as well as a pK7-GFP control vector expressing along the GFP were used to transfect the protoplasts. Transfected protoplasts were further incubated at $22{ }^{\circ} \mathrm{C}$ in the dark for $16-20 \mathrm{~h}$ before observation under the confocal microscopy.

For leaf-infiltration, A. tumefaciens strain GV3101 harboring the respective pK7-based vectors was grown to an $\mathrm{OD}_{600}$ and resuspended in an infiltration medium (10 mM MES buffered MS medium containing 3\% sucrose and $200 \mu \mathrm{m}$ acetosyringone, $\mathrm{pH}$ 6.1). After $2-3 \mathrm{~h}$ incubation at room temperature, the agrobacterium suspension was used to infiltrate mature leaves of 4-week-old $N$. benthamiana plants. One day after the infiltration, the leaves were detached, and the epidermis was used for confocal microscopic observation.

To generated stable transgenic lines in P. hybrida cv 'Mitchell Diploid' (MD, or W115), A. tumefaciens strain GV3101 harboring the proLIS-JsBEAT1-GFP or proLIS-JsBEAT2-GFP vector (Section 4.3) was used to transform leaf explants following a standard method [40]. Transformant was selected on $100 \mathrm{mg} \mathrm{L}^{-1}$ kanamycin medium for regeneration. Regenerated plants derived from the T0 generation were further screened by PCR amplification of a nptII gene fragment. Transgenic plants among the progenies from T0 and subsequent $\mathrm{T} 1$ generations were selected by germinating the seeds on kanamycin-containing MS medium. Positive transgenic T2 generation was used for phenotypic examination, genetic verification (Figure S6) and floral volatile determination.

\subsection{Confocal Fluorescence Microscopy}

A Leica TCS SP8 confocal microscope (Leica Microsystems GmbH, Wetzlar, Germany) was used to monitor signals for GFP (excitation at $470 / 40 \mathrm{~nm}$, emission at $164525 / 50 \mathrm{~nm}$ ) and for chlorophyll autofluorescence (excitation at $545 / 30 \mathrm{~nm}$, emission at $620 / 60 \mathrm{~nm}$ ) in specimens from protoplasts, leaf epidermis, and petals.

\subsection{Statistical Analysis}

Quantitative data were reported as mean \pm SD (standard deviation) from three independent experiments or from three biological replications. When appropriate, significant difference between pair or among groups of treatments/samples was checked by T-test or ANOVA multiple tests using the software GraphPad Prism version 8.3.

\subsection{Accession Number}

The coding sequences have been submitted to NCBI GenBank under the accession numbers OK507197 for the JsBEAT1 and OK507198 for JsBEAT2.

Supplementary Materials: The following are available online at https:/ /www.mdpi.com/article/10 $.3390 /$ plants11010013/s1: Figure S1: Tentative identification of the floral volatile compounds with GS-MS based on the retention index (RI) and the MS spectrum comparing with that in the NIST11 (National Institute of Standards and Technology) GC-MS database; Figure S2: Expression profile of BAHD homologous genes in J. sambac transcriptomes; Figure S3: A Neighbor-Joining tree showing the phylogenetic relationship of the J. sambac BAHD-like proteins with known members from other plants; Figure S4: Amino acid sequence alignment of the $7 \mathrm{~J}$. sambac BAHD-like proteins showing the highly conserved HXXXD and DFGWG motifs; Figure S5: Representative images showing subcellular localization of the C-terminus-tagged GFP fusion of JsBEAT1 or JsBEAT2.; Figure S6: Production of JsBEAT1 and JsBEAT2 recombinant proteins in E. coli; Figure S7: Generation and verification of transgenic $P$. hybrida plants ectopically expressing JsBEAT1-GFP and JsBEAT2-GFP driven by a floral-specific promoter from the CbLIS gene; Figure S8: Representative GC-MS chromatograms in petal hexane extracts of P. hybrida W115 and transgenic plants; Figure S9: Putative identification of floral volatile benzenoid/phenylpropanoid compounds in GC-MS analysis of P. hybrida corolla hexane extracts; Table S1: Prediction of subcellular localization of the JsBEATs; Table S2: List of primers used in this study. 


\begin{abstract}
Author Contributions: Conceptualization, Y.W. and B.W.; data curation, M.L.; formal analysis, Y.W., H.Z., C.W., X.H. and J.H.; funding acquisition, Y.Y. and B.W.; investigation, Y.W., H.Z. and C.W.; methodology, Y.W., X.H. and Y.Y.; project administration, M.L. and Y.Y.; supervision, B.W.; validation, J.H., M.L. and Y.Y.; visualization, Y.W. and B.W.; writing-original draft, Y.W.; writing-review and editing, B.W. All authors have read and agreed to the published version of the manuscript.
\end{abstract}

Funding: This work was funded in part by a grant from the National Natural Science Foundation of China (NSFC) Nr. 31902050 to Y.Y.

Institutional Review Board Statement: Not applicable.

Informed Consent Statement: Not applicable.

Data Availability Statement: All data supporting the findings of this study are available within the paper and within its Supplementary Materials published online. Further information may be obtained from the corresponding author, B.W.

Acknowledgments: We thank Mohammad-Reza Hajirezaei (Leibniz Institute of Plant Genetics and Crop Plant Research, Gatersleben, Germany) for providing the petunia seeds used in this study. We are grateful for the excellent technical assistance from Yongyan Zhang and Wei Wang.

Conflicts of Interest: The authors declare no conflict of interest.

\title{
References
}

1. Leong, B.J.; Last, R.L. Promiscuity, impersonation and accommodation: Evolution of plant specialized metabolism. Curr. Opin. Struct. Biol. 2017, 47, 105-112. [CrossRef]

2. Pichersky, E.; Lewinsohn, E. Convergent evolution in plant specialized metabolism. Annu. Rev. Plant Biol. 2011, 62, 549-566. [CrossRef]

3. Pichersky, E.; Noel, J.P.; Dudareva, N. Biosynthesis of plant volatiles: Nature's diversity and ingenuity. Science 2006, 311, 808-811. [CrossRef]

4. Knudsen, J.T.; Eriksson, R.; Gershenzon, J.; Stahl, B. Diversity and distribution of floral scent. Bot. Rev. 2006, 72, 1-120. [CrossRef]

5. Muhlemann, J.K.; Klempien, A.; Dudareva, N. Floral volatiles: From biosynthesis to function. Plant Cell Env. 2014, 37, 1936-1949. [CrossRef]

6. Schiestl, F.P. Ecology and evolution of floral volatile-mediated information transfer in plants. New Phytol. 2015, 206, 571-577. [CrossRef]

7. Kantsa, A.; Raguso, R.A.; Dyer, A.G.; Olesen, J.M.; Tscheulin, T.; Petanidou, T. Disentangling the role of floral sensory stimuli in pollination networks. Nat. Commun. 2018, 9, 1041. [CrossRef]

8. de Groot, A.C.; Schmidt, E. Essential Oils, Part VI: Sandalwood Oil, Ylang-Ylang Oil, and Jasmine Absolute. Dermatitis 2017, 28, 14-21. [CrossRef]

9. Bera, P.; Kotamreddy, J.N.; Samanta, T.; Maiti, S.; Mitra, A. Inter-specific variation in headspace scent volatiles composition of four commercially cultivated jasmine flowers. Nat. Prod. Res. 2015, 29, 1328-1335. [CrossRef]

10. Barman, M.; Mitra, A. Temporal relationship between emitted and endogenous floral scent volatiles in summer- and winterblooming Jasminum species. Physiol. Plant. 2019, 166, 946-959. [CrossRef]

11. Yu, Y.; Lyu, S.; Chen, D.; Lin, Y.; Chen, J.; Chen, G.; Ye, N. Volatiles Emitted at Different Flowering Stages of Jasminum sambac and Expression of Genes Related to $\alpha$-Farnesene Biosynthesis. Molecules 2017, 22, 546. [CrossRef]

12. Pragadheesh, V.S.; Chanotiya, C.S.; Rastogi, S.; Shasany, A.K. Scent from Jasminum grandiflorum flowers: Investigation of the change in linalool enantiomers at various developmental stages using chemical and molecular methods. Phytochemistry 2017, 140, 83-94. [CrossRef]

13. Bera, P.; Mukherjee, C.; Mitra, A. Enzymatic production and emission of floral scent volatiles in Jasminum sambac. Plant Sci. Int. J. Exp. Plant Biol. 2017, 256, 25-38. [CrossRef]

14. Pragadheesh, V.S.; Yadav, A.; Chanotiya, C.S.; Rout, P.K.; Uniyal, G.C. Monitoring the Emission of Volatile Organic Compounds from Flowers of Jasminum sambac Using Solid-Phase Micro-extraction Fibers and Gas Chromatography with Mass Spectrometry Detection. Nat. Prod. Commun. 2011, 6, 1333-1338. [CrossRef]

15. D'Auria, J.C. Acyltransferases in plants: A good time to be BAHD. Curr. Opin. Plant Biol. 2006, 9, 331-340. [CrossRef]

16. St-Pierre, B.; Laflamme, P.; Alarco, A.M.; De Luca, V. The terminal O-acetyltransferase involved in vindoline biosynthesis defines a new class of proteins responsible for coenzyme A-dependent acyl transfer. Plant J. 1998, 14, 703-713. [CrossRef]

17. Dudareva, N.; D’Auria, J.C.; Nam, K.H.; Raguso, R.A.; Pichersky, E. Acetyl-CoA:benzylalcohol acetyltransferase-an enzyme involved in floral scent production in Clarkia breweri. Plant J. 1998, 14, 297-304. [CrossRef]

18. Yang, Q.; Reinhard, K.; Schiltz, E.; Matern, U. Characterization and heterologous expression of hydroxycinnamoyl/benzoylCoA:anthranilate N-hydroxycinnamoyl/benzoyltransferase from elicited cell cultures of carnation, Dianthus caryophyllus L. Plant Mol. Biol. 1997, 35, 777-789. [CrossRef] 
19. Bontpart, T.; Cheynier, V.; Ageorges, A.; Terrier, N. BAHD or SCPL acyltransferase? What a dilemma for acylation in the world of plant phenolic compounds. New Phytol. 2015, 208, 695-707. [CrossRef]

20. Ma, X.Y.; Koepke, J.; Panjikar, S.; Fritzsch, G.; Stockigt, J. Crystal structure of vinorine synthase, the first representative of the BAHD superfamily. J. Biol. Chem. 2005, 280, 13576-13583. [CrossRef]

21. Tuominen, L.K.; Johnson, V.E.; Tsai, C.J. Differential phylogenetic expansions in BAHD acyltransferases across five angiosperm taxa and evidence of divergent expression among Populus paralogues. BMC Genom. 2011, 12, 236. [CrossRef]

22. Wang, P.P.; Wei, P.N.; Niu, F.F.; Liu, X.F.; Zhang, H.L.; Lyu, M.L.; Yuan, Y.; Wu, B.H. Cloning and Functional Assessments of Floral-Expressed SWEET Transporter Genes from Jasminum sambac. Int. J. Mol. Sci. 2019, 20, 4001. [CrossRef]

23. D'Auria, J.C.; Chen, F.; Pichersky, E. Characterization of an Acyltransferase Capable of Synthesizing Benzylbenzoate and Other Volatile Esters in Flowers and Damaged Leaves of Clarkia breweri. Plant Physiol. 2002, 130, 466-476. [CrossRef]

24. Boatright, J.; Negre, F.; Chen, X.; Kish, C.M.; Wood, B.; Peel, G.; Orlova, I.; Gang, D.; Rhodes, D.; Dudareva, N. Understanding in vivo benzenoid metabolism in petunia petal tissue. Plant Physiol. 2004, 135, 1993-2011. [CrossRef]

25. Chedgy, R.J.; Kollner, T.G.; Constabel, C.P. Functional characterization of two acyltransferases from Populus trichocarpa capable of synthesizing benzyl benzoate and salicyl benzoate, potential intermediates in salicinoid phenolic glycoside biosynthesis. Phytochemistry 2015, 113, 149-159. [CrossRef]

26. Adebesin, F.; Widhalm, J.R.; Boachon, B.; Lefevre, F.; Pierman, B.; Lynch, J.H.; Alam, I.; Junqueira, B.; Benke, R.; Ray, S.; et al. Emission of volatile organic compounds from petunia flowers is facilitated by an ABC transporter. Science 2017, 356, 1386-1388. [CrossRef]

27. Dudareva, N.; Cseke, L.; Blanc, V.M.; Pichersky, E. Evolution of floral scent in Clarkia: Novel patterns of S-linalool synthase gene expression in the C. breweri flower. Plant Cell 1996, 8, 1137-1148. [CrossRef]

28. Klempien, A.; Kaminaga, Y.; Qualley, A.; Nagegowda, D.A.; Widhalm, J.R.; Orlova, I.; Shasany, A.K.; Taguchi, G.; Kish, C.M.; Cooper, B.R.; et al. Contribution of CoA ligases to benzenoid biosynthesis in petunia flowers. Plant Cell 2012, 24, 2015-2030. [CrossRef]

29. Colquhoun, T.A.; Marciniak, D.M.; Wedde, A.E.; Kim, J.Y.; Schwieterman, M.L.; Levin, L.A.; Van Moerkercke, A.; Schuurink, R.C.; Clark, D.G. A peroxisomally localized acyl-activating enzyme is required for volatile benzenoid formation in a Petunia $\mathrm{x}$ hybrida cv. 'Mitchell Diploid' flower. J. Exp. Bot. 2012, 63, 4821-4833. [CrossRef]

30. Dexter, R.; Qualley, A.; Kish, C.M.; Ma, C.J.; Koeduka, T.; Nagegowda, D.A.; Dudareva, N.; Pichersky, E.; Clark, D. Characterization of a petunia acetyltransferase involved in the biosynthesis of the floral volatile isoeugenol. Plant J. 2007, 49, 265-275. [CrossRef]

31. Wang, J.; De Luca, V. The biosynthesis and regulation of biosynthesis of Concord grape fruit esters, including 'foxy' methylanthranilate. Plant J. 2005, 44, 606-619. [CrossRef]

32. D'Auria, J.C.; Reichelt, M.; Luck, K.; Svatoš, A.; Gershenzon, J. Identification and characterization of the BAHD acyltransferase malonyl CoA:anthocyanidin 5-O-glucoside-6"-O-malonyltransferase (At5MAT) in Arabidopsis thaliana. FEBS Lett. 2007, 581, 872-878. [CrossRef]

33. Oshikiri, H.; Watanabe, B.; Yamamoto, H.; Yazaki, K.; Takanashi, K. Two BAHD Acyltransferases Catalyze the Last Step in the Shikonin/Alkannin Biosynthetic Pathway. Plant Physiol. 2020, 184, 753-761. [CrossRef]

34. Werner, V.; Petersen, M. A BAHD hydroxycinnamoyltransferase from Actaea racemosa catalyses the formation of fukinolic and cimicifugic acids. Planta 2019, 250, 475-485. [CrossRef]

35. Legrand, G.; Delporte, M.; Khelifi, C.; Harant, A.; Vuylsteker, C.; Mörchen, M.; Hance, P.; Hilbert, J.L.; Gagneul, D. Identification and Characterization of Five BAHD Acyltransferases Involved in Hydroxycinnamoyl Ester Metabolism in Chicory. Front. Plant Sci. 2016, 7, 741. [CrossRef]

36. Colquhoun, T.A.; Verdonk, J.C.; Schimmel, B.C.J.; Tieman, D.M.; Underwood, B.A.; Clark, D.G. Petunia floral volatile benzenoid/phenylpropanoid genes are regulated in a similar manner. Phytochemistry 2010, 71, 158-167. [CrossRef]

37. Karimi, M.; Inze, D.; Depicker, A. GATEWAY vectors for Agrobacterium-mediated plant transformation. Trends Plant Sci. 2002, 7, 193-195. [CrossRef]

38. Katoh, K.; Toh, H. Recent developments in the MAFFT multiple sequence alignment program. Brief. Bioinform. 2008, 9, $286-298$. [CrossRef]

39. Larkin, M.A.; Blackshields, G.; Brown, N.P.; Chenna, R.; McGettigan, P.A.; McWilliam, H.; Valentin, F.; Wallace, I.M.; Wilm, A.; Lopez, R.; et al. Clustal W and Clustal X version 2.0. Bioinformatics 2007, 23, 2947-2948. [CrossRef]

40. Horsch, R.B.; Fry, J.E.; Hoffmann, N.L.; Wallroth, M.; Eichholtz, D.; Rogers, S.G.; Fraley, R.T. A Simple and General Method for Transferring Genes into Plants. Science 1985, 227, 1229-1231. [CrossRef] 